Supporting Information for

\title{
A Novel D-A-D-type Supramolecular Aggregates with High Photoelectric Activity for Construction of Ultrasensitive Photoelectrochemical Biosensor
}

Han-Mei Deng, Ming-Hui Zhu, Liao-Jing Huang, Ya-Qin Chai, Xiao-Rui Liu,

$$
\text { Ruo Yuan*,Ya-Li Yuan* }
$$

Key Laboratory of Luminescent and Real-Time Analytical Chemistry (Southwest

University), Ministry of Education, College of Chemistry and Chemical

Engineering, Southwest University, Chongqing 400715, PR China

* Corresponding author. Tel.: +86-23-68252277; Fax: +86-23-68253172.

E-mail address: yuanruo@,swu.edu.cn, y198688@swu.edu.cn;

Contents of the Supporting Information:

Reagents and Materials----S2

Apparatus----S3

Structure Characteristics of HPDS Aggregate----S4

Simulation of the Arrangement Structure of HPDS Aggregate----S5

Optimization of the Reaction Conditions----S6

Other Tables----S7 


\section{Reagents and Materials}

Perylene-3, 4, 9, 10-tetracarboxylic dianhydride (PTCDA) and melamine were purchased from LianGang Dyestuff Chemicals Co. Ltd (Liaoning, China). Hydrazine monohydrate $\left(\mathrm{N}_{2} \mathrm{H}_{2} \cdot \mathrm{H}_{2} \mathrm{O}, \quad 80 \% \quad\right.$ W/V $)$, glutaraldehyde $\left(\mathrm{C}_{5} \mathrm{H}_{8} \mathrm{O}_{2}, \quad 50 \% \quad\right.$ W/V $)$, ethylenediamine $\left(\mathrm{C}_{2} \mathrm{H}_{8} \mathrm{~N}_{2}\right)$, acetonitrile $\left(\mathrm{CH}_{3} \mathrm{CN}\right)$ and ethanol were provided by Kelon Co. Ltd (Chengdu, China). Gold chloride $\left(\mathrm{HAuCl}_{4}\right)$, ammonium hydroxide $\left(\mathrm{NH}_{3} \cdot \mathrm{H}_{2} \mathrm{O}\right.$, $28 \% \mathrm{~W} / \mathrm{V}$ ), hexanethiol (HT), tetraethyl orthosilane (TEOS) and 3-aminopropyl triethoxysilane (APTES) were bought from Sigma Chemical Co. (St. Louis. MO, USA). Tetrabutylammonium hexafluorophosphate $\left(\mathrm{Bu}_{4} \mathrm{NPF}_{6}\right)$ was obtained from Macklin Biochemical Co. Ltd (Shanghai, China). Ferrocene $\left(\mathrm{C}_{10} \mathrm{H}_{10} \mathrm{Fe}\right)$ was bought by TCI Development Co. Ltd. (Shanghai, China). Phosphate buffered solution (PBS, pH 7.0, 0.1 M) was prepared by $0.1 \mathrm{M} \mathrm{Na}_{2} \mathrm{HPO}_{4}, 0.1 \mathrm{M} \mathrm{KH}_{2} \mathrm{PO}_{4}$, and $0.1 \mathrm{M} \mathrm{KCl}$. Tris-HCl buffer was prepared by $20 \mathrm{mM}$ Tris-HCl $140 \mathrm{mM} \mathrm{NaCl}, 5 \mathrm{mM} \mathrm{KCl}$ and 1 $\mathrm{mM} \mathrm{CaCl} 2$. The oligonucleotides (Table S1), Exonuclease III (Exo III) and $10 \times \mathrm{NE}$ Buffer were acquired from Sangon Biotech Co. Ltd (Shanghai, China). 
Table S1. Information of Oligonucleotide Sequences in this Experiment

\begin{tabular}{|c|c|}
\hline Name & Sequence (5'-3') \\
\hline Hairpin 1 & $\begin{array}{l}\text { AAG CTG GGA TAC GTC CTC TTT ATC ACT ACC TCT CTA TTA CAC } \\
\text { AAG CTG GGA TAC GTC CTC TAG TGA TAA AGA GGA CGT ATC CCA } \\
\text { GCT TGG GGG CAG CGC }\end{array}$ \\
\hline Hairpin 2 & $\begin{array}{l}\text { AAG CTG GGA TAC GTC CTC TTT ATC ACT ACC TCT CTA TTA CAC } \\
\text { AAG CTG GGA TAC GTC CTC TAG TGA TAA AGA GGA CGT ATC CCA } \\
\text { GCT TCT CAC AAC CTC }\end{array}$ \\
\hline TP53 & GAG GTT GTG AGG CGC TGC CCC CAC CAT G \\
\hline Hairpin 3 & SH-GGG ATA CGT CCT CGC CTA GCC CCG TAT CCC AGC TT \\
\hline Capture DNA & TTT TTC GCC TTT TGT AGG CGA GGA CGT ATT TTT \\
\hline
\end{tabular}

\section{Apparatus}

The PEC measurement was performed on a PEC workstation (Ivium, Netherlands). Excitation light source was supplied by the LED lamp and switched off-on-off for 10-20-10 s under $0.0 \mathrm{~V}$ potential. Electrochemical deposition of $\mathrm{Au}$ nanoparticles $(\operatorname{depAu})$ was conducted in $1 \% \mathrm{~W} / \mathrm{V} \mathrm{HAuCl} l_{4}$ aqueous solution under -0.2 V for $30 \mathrm{~s}$. Electrochemical impedance spectroscopy (EIS) measurement was operated by the $\mathrm{CHI} 660 \mathrm{e}$ electrochemical workstation in $\left[\mathrm{Fe}(\mathrm{CN})_{6}\right]^{3-/ 4-}$ solution $(5.0 \mathrm{mM}, \mathrm{pH}$ 7.0) at frequency ranging from $5 \times 10^{-2}$ to $1 \times 10^{6} \mathrm{~Hz}$. The morphologies of various nanomaterials and energy-dispersive X-ray spectroscopy (SEM-EDS) were characterized by the scanning electron microscopy (SEM, S-4800, Hitachi, Japan). The photophysical characterizations were recorded with a UV-2550 UV/Vis spectrophotometer (Shimadzu, Tokyo, Japan). The polyacrylamide gel electrophoresis was implemented with BG-ver MIDI electrophoresis apparatus (Baygene, Beijing, 
China) and the image of gels was taken by Doc XR+ system (Bio-Rad, California, USA). Mass spectrogram was record by mass spectrograph (Impact II, Bruker, USA).

\section{Structure Characteristics of HPDS Aggregate}

Infrared (IR) spectra, UV-vis absorption spectrum and the high resolution mass spectrometry (HRMS) were carried out for further exploring the structure and molecular mass of HPDS. As shown in Figure S1A, IR spectra of the HPDS displayed the carbonyl $(\mathrm{C}=\mathrm{O})$ stretching vibration frequency of the imide (-CO-NH-) at 1663.19 $\mathrm{cm}^{-1}$ and $1691.22 \mathrm{~cm}^{-1}$. And the strong absorption peak, belonged to the stretch vibration frequency of amine $(\mathrm{C}-\mathrm{N})$, appeared at $1365 \mathrm{~cm}^{-1}$. Obviously, characteristic absorption peaks of anhydride (-COOOC-) in the range of $1700 \mathrm{~cm}^{-1}$ to $1900 \mathrm{~cm}^{-1}$ were undetectable, manifesting that anhydride (-COOOC-) group was completely converted into imide structure without mono-substituted products. Simultaneously, characteristic absorption peaks of the stretch vibration frequency of free primary amine $\left(-\mathrm{NH}_{2}\right)$ was visible at $3446.42 \mathrm{~cm}^{-1}$ and $3325.21 \mathrm{~cm}^{-1}$. In addition, UV-vis absorption spectrum was shown in Figure S1B. In the range of 400 to $600 \mathrm{~nm}$, the characteristic absorption peaks of PTCDA was observed (curve a), which dominated by the $n-\pi *$ transition of the perylene anhydride. The $n-\pi^{*}$ transition absorption peaks of PTCA were located at $466 \mathrm{~nm}$ and $550 \mathrm{~nm}$ (curve b). By contrast, the absorption peaks of HPDS, which were located at $478 \mathrm{~nm}$ and $586 \mathrm{~nm}$ (curve c), showed evidently red shift as a result of increased electron delocalization of conjugated system. Afterwards, purified HPDS power dissolved in dimethyl sulfoxide (DMSO)

solvent was characterized to evaluate the molecular mass by HRMS. The 
mass-to-charge ratio (m/z) was 420.0854 (Figure $\mathrm{S} 1 \mathrm{C}$ ), which was suitable for the relative molecular mass of $\mathrm{C}_{24} \mathrm{H}_{12} \mathrm{~N}_{4} \mathrm{O}_{4}$ as expected. In conclusion, the results of IR spectra, UV-vis absorption spectrum, HRMS analysis and fore-mentioned elemental content testing (EDS analysis) were coincide with each other, fully proved the successful synthesis of HPDS nanomaterial.

A

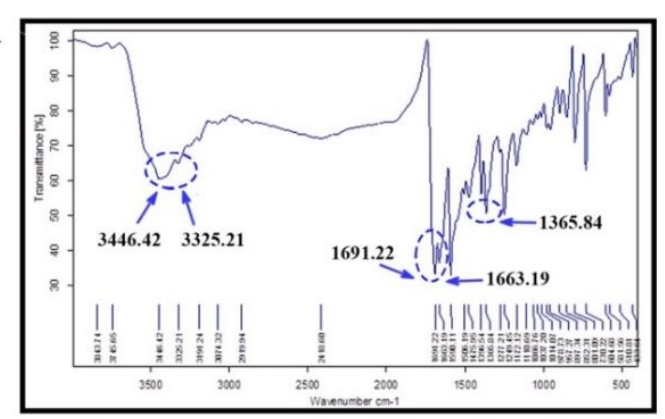

B

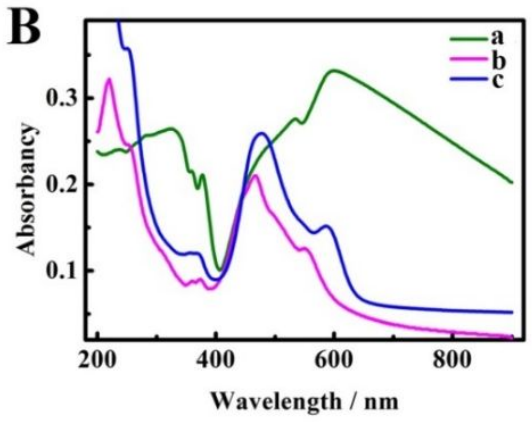

C

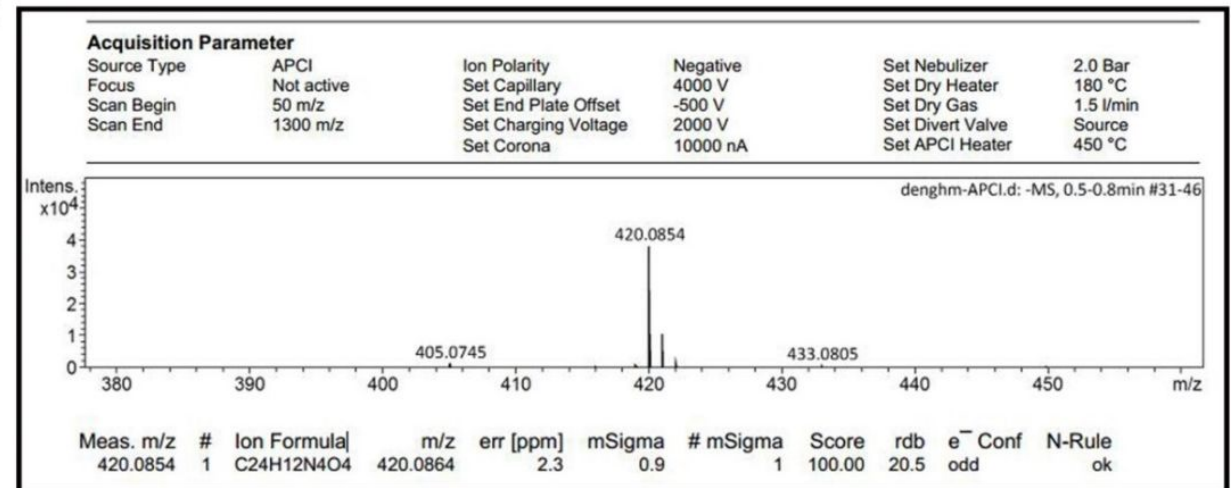

Figure S1 (A) IR spectra analysis of the synthesized HPDS nanomaterials. (B) UV-vis absorption spectrum of (a) PTCDA, (b) PTCA and (c) HPDS, and (C) High resolution mass spectrometry of the synthesized HPDS.

\section{Simulation of the Arrangement Structure of HPDS Aggregate}

Molecular structure and arrangement of HPDS aggregate were simulated by the polymorphic module in Material Studio software. ${ }^{1}$ The corresponding crystal structure at side view were shown in Figure S2A, adjacent molecules were linked together by $\mathrm{N}$ 
$-\mathrm{H} \cdots \mathrm{O}$ hydrogen bonds with length about $2.068 \AA$ or $2.072 \AA$ at both side chain, and the face-to-face molecular arranged in a $\pi$ - $\pi$-stacked layers with the minimum interplanar spacing of $3.44 \AA$. Usually, in the crystal, following space groups, $P 1$, $P 2_{1} / c, P 2{ }_{1} 2_{1} 2_{1}, P 2_{1}, C 2 / c, P n a 2_{1}, P b c a, P b c n, C C$, and $C_{2}$ are the most probable ones in accordance with statistics from the Cambridge Structural Database. ${ }^{2}$ Accordingly, the polymorphic calculation was performed in these space groups. According to sorting by total energy for all of the structures, the crystal structures of HPDS aggregates molecule with the lowest total energies belonged to the space groups of $P 2_{1}$ was exhibited at Figure S2B. Additionally, Figure $6 \mathrm{C}$ revealed space arrangement of HPDS aggregate from the top to bottom view.

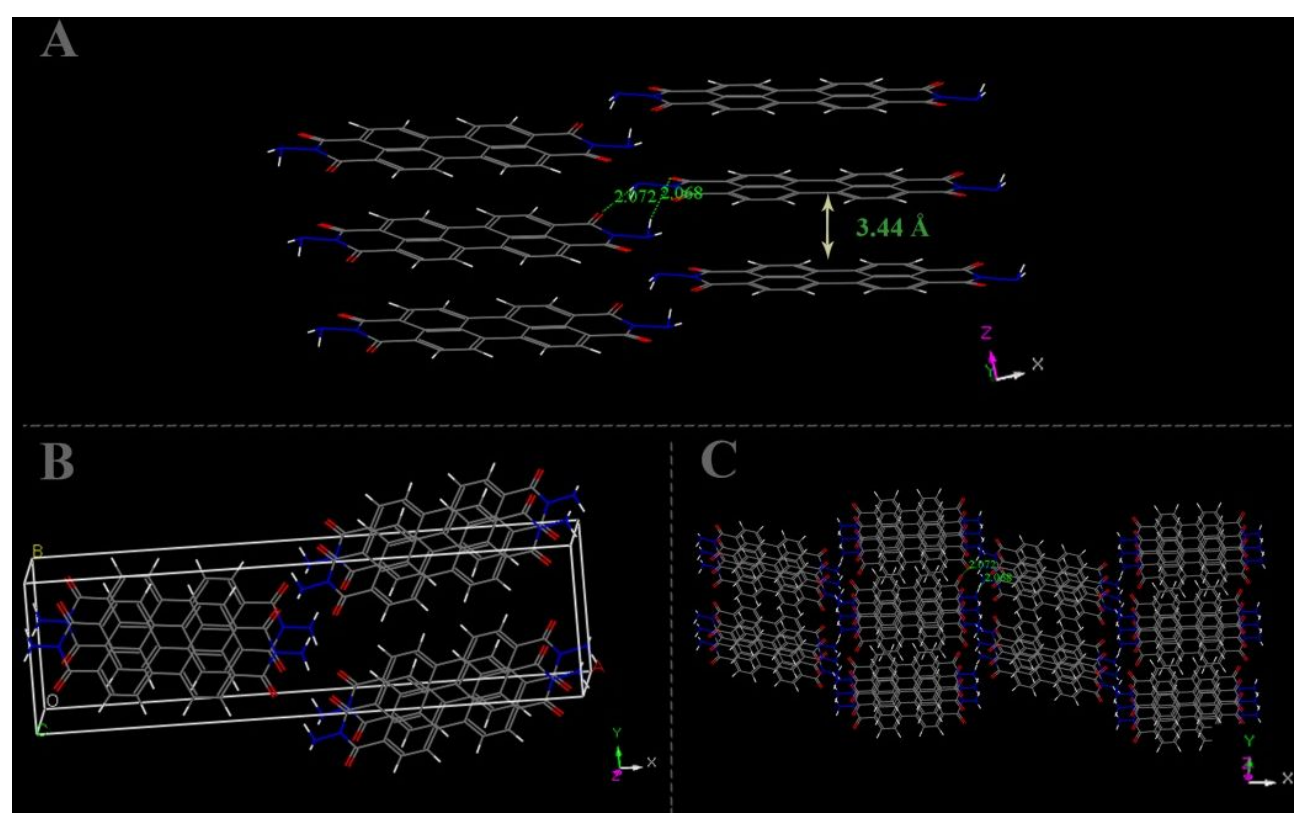

Figure S2. (A) Crystal structures at side view, (B) space groups and (C) space arrangement from top to bottom view of HPDS aggregate 


\section{Optimization of the Reaction Conditions}

In the presence of target DNA, double bipedal DNA walker cascade amplification reaction only could be initiated by Exo III, thus the concentration and the reaction time of Exo III were investigated to improve the performance of the proposed biosensor. As shown in Figure S3A, the photocurrent response decreased accordingly with the increase of the concentration of the Exo III and tended to be gentle at $25 \mathrm{U}$ Exo III. Therefore, $25 \mathrm{U}$ was confirmed as optimization concentration for the entire experiment. Figure S3B exhibited the trend of photocurrent response with the digestion time of the Exo III, and the photocurrent response decreased continuously with the increased digestion time and eventually stabilized at 30 mins. Consequently, 30 mins was selected as optimal digestion time of Exo III.
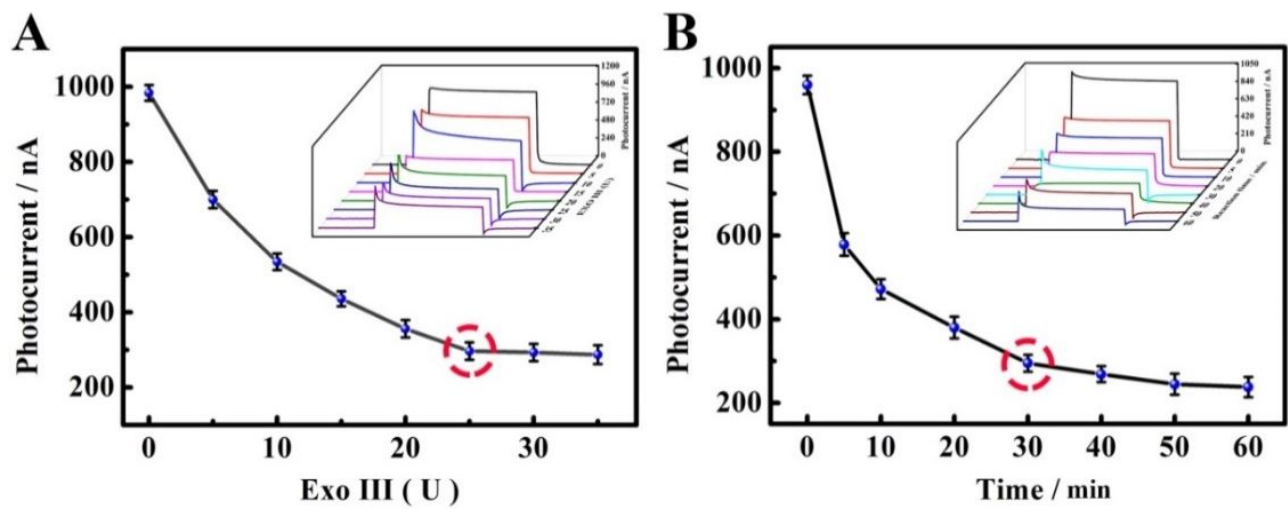

Figure S3. Optimizations of (A) Exo III concentration and (B) digestion time (Insert: corresponding photocurrent signals diagram). 
Table S2. The comparison of the proposed biosensor with other various biosensors

\begin{tabular}{cccc}
\hline Detection method & $\begin{array}{c}\text { detection } \\
\text { range }\end{array}$ & $\begin{array}{c}\text { detection } \\
\text { limit }\end{array}$ & reference \\
\hline Fluorescence & $20 \mathrm{fM}-500 \mathrm{pM}$ & $4.1 \mathrm{fM}$ & 3 \\
\hline Electrochemiluminescence & $10 \mathrm{fM}-100 \mathrm{pM}$ & $3.3 \mathrm{fM}$ & 4 \\
\hline Electrochemistry & $100 \mathrm{fM}-100 \mathrm{nM}$ & $33.6 \mathrm{fM}$ & 5 \\
\hline Fluorescence & $100 \mathrm{fM}-10 \mathrm{pM}$ & $81 \mathrm{fM}$ & 6 \\
\hline Electrochemistry & $50 \mathrm{fM}-500 \mathrm{fM}$ & $36 \mathrm{fM}$ & 7 \\
PEC & $2 \mathrm{fM}-50 \mathrm{nM}$ & $0.64 \mathrm{fM}$ & Our work \\
\hline
\end{tabular}

Table S3. Measurement of target in healthy serum with proposed biosensor

\begin{tabular}{ccccc}
\hline \hline Sample & Added/pM & found/pM & Recovery/\% & RSD/\% \\
\hline $\mathbf{1}$ & 0.01 & 0.01024 & 102.4 & 7.8 \\
$\mathbf{2}$ & 1 & 0.9260 & 92.60 & 2.1 \\
$\mathbf{3}$ & 10 & 10.75 & 107.5 & 1.5 \\
$\mathbf{4}$ & 1000 & 1012.1 & 101.2 & 3.6 \\
\hline \hline
\end{tabular}

\section{REFERENCES}

(1) Day, G.; Motherwell, W.; Ammon, H.; Boerrigter, S.; Della Valle, R.; Venuti, E.; Dzyabchenko, A.; Dunitz, J.; Schweizer, B.; Van Eijck, B. A Third Blind Test of Crystal Structure Prediction. Acta Crystallogr. B. 2005, 61, 511-527.

(2) Liu, H. Y.; Liu, X. R. Strategy to Modulate the $\pi$-bridged Units in Bis (4-methoxyphenyl) amine-based Hole-transporting Materials for Improvement of Perovskite Solar Cell Performance. J. Mater. Chem. C. 2018, 6, 6816.

(3) Li, W.; Wang, L.; Jiang, W. A catalytic assembled enzyme-free three-dimensional 
DNA walker and its sensing application. Chem. Commun. 2017, 53, 5527-5530.

(4) Xu, Z. Q.; Liao, L. L.; Chai, Y. Q.; Wang, H. J.; Yuan, R. Ultrasensitive Electrochemiluminescence Biosensor for MicroRNA Detection by 3D DNA Walking Machine Based Target Conversion and Distance-Controllable Signal Quenching and Enhancing. Anal. Chem. 2017, 89, 8282-8287.

(5) Yan, T. T.; Zhu, L. Y.; Ju, H. X.; Lei, J. P. DNA-Walker-Induced Allosteric Switch for Tandem Signal Amplification with Palladium Nanoparticles/Metal-Organic Framework Tags in Electrochemical Biosensing. Anal. Chem. 2018, 90, 14493-14499.

(6) Zhu, L. Y.; Liu, Q. H.; Yang, B. Y.; Ju, H. X.; Lei, J. P. Pixel Counting of Fluorescence Spots Triggered by DNA Walkers for Ultrasensitive Quantification of Nucleic Acid. Anal. Chem. 2018, 90, 6357-6361.

(7) Wang, K.; He, M. Q.; Zhai, F. H.; Wang, J.; He, R. H.; Yu, Y. L. Autonomous DNA Nanomachine based on Cascade Amplification of Strand Displacement and DNA Walker for Detection of Multiple DNAs. Biosens. Bioelectron. 2018, 105, $159-165$. 